\title{
A Meta-Analysis of the Impact of Obesity, Metabolic Syndrome, Insulin Resistance, and Microbiome on the Diagnosis of Barrett's Esophagus
}

\author{
Jia Di Yan Cheng Danyan Chang Yan Liu \\ Department of Gastroenterology, The Second Affiliated Hospital of Xi'an Jiaotong University, Xi'an, China
}

\section{Keywords}

Barrett's esophagus · Abdominal obesity · Metabolic syndrome $\cdot$ Insulin resistance $\cdot$ Microbiome

\begin{abstract}
Background and Aim: The etiology and pathogenesis of Barrett's esophagus $(\mathrm{BE})$ have been widely studied during recent decades. However, the association between $B E$ and possible risk factors, including abdominal obesity (AO), metabolic syndrome (MetS), insulin resistance (IR), and the microbiome has not reached a consensus and lacks a systematic assessment. The purpose of our study is to evaluate, quantify, and summarize the association between these factors and BE risk. Methods: A systematic search of Pubmed, Embase, and Cochrane Library databases was performed to identify relevant studies before September 2018. Studies were estimated with the $\mathrm{OR}$, the weighted mean difference (WMD), and the $95 \% \mathrm{Cl}$ by using a random effects model. Subgroup analysis and publication bias were also performed. Results: A total of 46 citations were included in the analysis, and 119,273 subjects were analyzed (AO 13, MetS 15, IR 9, and microbiome: 9). The pooled results showed that $A O(p<$ 0.01 , OR 1.30, 95\% Cl 1.11-1.52, $\left.I^{2}=31.9 \%\right)$, MetS $(p<0.01$, OR 1.68, 95\% Cl 1.40-2.01, $\left.P^{2}=87.6 \%\right)$, and IR $(p<0.01$, WMD $\left.0.23,95 \% \mathrm{Cl} 0.11-0.35, P^{2}=55.8 \%\right)$ were all significantly associated with an increased risk of $\mathrm{BE}$, but except for the mi-
\end{abstract}

crobiome ( $p>0.05$, OR 1.27, 95\% Cl 0.66-2.43, $\left.I^{2}=46.7 \%\right)$. In addition, subgroup analyses were stratified by waist-to-hip ratio, waist circumference, body mass index, diagnosis criteria, strain type, geographical region, and study design, respectively. Moreover, we observed no evidence of publication bias in Egger's and Begg's tests. Conclusions: Our study reveals that $A O$, MetS, and IR are significantly associated with $\mathrm{BE}$ risk, except for the microbiome. The mechanism of $\mathrm{BE}$ induced by 3 risk factors should be further explored.

(c) 2019 S. Karger AG, Basel

\section{Introduction}

Barrett's esophagus (BE) has been defined as a pathological state that the stratified squamous epithelium of distal esophagus has been replaced by metaplastic columnar epithelium with goblet cells. BE has received significant attention because it predisposes patients to esophageal adenocarcinoma (EAC) of which prevalence has increased to more than 7 folds over the past several decades [1]. The overall prevalence of BE in Western countries ranges from 1 to $25 \%[2,3]$, and the prevalence of histologically confirmed $\mathrm{BE}$ is $1.3 \%$ in Asia [4]. According to a recent epidemiological survey, the prevalence of $\mathrm{BE}$ is $1.6 \%$ in the general population [5]. Therefore, preventing $\mathrm{BE}$ based on risk factors will effectively reduce the preva-

\section{KARGER}

(C) 2019 S. Karger AG, Basel

karger@karger.com

www.karger.com/ddi
Yan Cheng, $\mathrm{MD}, \mathrm{PhD}$

Department of Gastroenterology

The Second Affiliated Hospital of Xi' an Jiaotong University

No. 157, Xi Wu Road, Xi'an, Shaanxi 710004 (China)

E-Mail drchengyan@163.com 
lence of EAC. Estimates have suggested that BE are attributable to a large number of risk factors, such as chronic gastroesophageal reflux disease symptoms, advancing age, male gender, and tobacco use $[6,7]$. In recent years, scholars have paid considerable attention to the association between BE risk and abdominal obesity (AO), metabolic syndrome (MetS), insulin resistance (IR), and the microbiome [8-13].

$\mathrm{AO}$ is a state of excessive abdominal fat around the stomach and abdomen, and is more likely associated with an increased risk of multiple chronic diseases, including diabetes, cardiovascular disease, and gastroesophageal cancer $[14,15]$. Waist-to-hip ratio (WHR), waist circumference (WC), and body mass index (BMI) are main measures to categorize $\mathrm{AO}$ based on the value: WHR $>0.90$ for men, WHR $>0.85$ for women; WC $>102$ $\mathrm{cm}$ for men, WC $>88 \mathrm{~cm}$ for women; BMI $\geq 30 \mathrm{~kg} / \mathrm{m}^{2}$ for men and women. MetS is a syndrome that contains more than three-fifths of medical conditions, including AO, high blood pressure, high blood sugar, high serum triglycerides, and low serum high-density lipoprotein. The diagnostic criteria for MetS mainly focus on the National Cholesterol Education Program Adult Treatment Panel III (NCEP ATP III) and the International Diabetes Federation (IDF) [16, 17]. IR is considered as a pathological condition in which cells fail to respond normally to the hormone insulin [18]. Homeostasis model assessment of IR (HOMA-IR) has been noted to be the most useful indicator for assessing an individual's IR [19]. Many studies associated with IR are directly involved in glucose metabolism, and abnormal glucose has the ability to upregulate insulin-related signaling pathways in $\mathrm{BE}$ tissue [20]. Microbiome is the microorganism in the body and a part of the body. Recently, microbiome alterations have been implicated in the pathogenesis of inflammatory and neoplastic conditions in the gastrointestinal tract, especially in the esophagus [21]. Very recently, scholars have studied the alterations of the microbiome in BE, which mainly focused on Campylobacter, Proteobacteria, Firmicutes, Streptococcus, Bacteroidetes, and Actinobacteria $[22,23]$.

The association between $\mathrm{BE}$ and possible risk factors, including AO, MetS, IR, and the microbiome, has not reached a consensus and lacks systematic assessments. Some studies report that AO, MetS, IR, and the microbiome are supposed to be risk factors for BE [24-28]. However, the opponents point out that the association is generally originated from single-center studies which lack the sample size required for sufficient precision of statistical associations between risk factors and $\mathrm{BE}$, and they have a dispute about risk factors associated with the development of $\mathrm{BE}[29,30]$.

The main aim of this meta-analysis is to evaluate, quantify, and summarize the association between $\mathrm{BE}$ and $\mathrm{AO}, \mathrm{MetS}, \mathrm{IR}$, and the microbiome by the subgroup analysis of WHR, WC, BMI, diagnosis criteria, strain type, geographical region, and study design where possible.

\section{Methods}

Search Strategy

Pubmed, Embase, and Cochrane Library databases were searched to identify relevant studies until September 2018. Search terms included a combination of "AO" or "central adiposity" or "visceral obesity," "metabolic disease" or "MetS," "IR" or "insulin sensitivity," "microbiome" or "microbial" and "BE" or "Barrett esophagus" or "BE". Cited studies and references of relevant studies were performed manually to search for additional studies.

\section{Selection Criteria}

Studies were included when the following criteria were fulfilled: (1) Case-control and cohort studies were chosen to assess the association between BE and 4 factors: AO, MetS, IR and microbiome; (2) Accurate definition of BE with histological evidence; (3) Well-defined AO estimated by $\left(\mathrm{BMI}, \mathrm{kg} / \mathrm{m}^{2}\right)$, homeostasis model of assessment for IR (HOMA-IR) was calculated according to the standard formula (plasma glucose $[\mathrm{mmol} / \mathrm{L}] \times$ serum insulin $[\mathrm{mLU} / \mathrm{L}]) / 22.5$, and clear diagnosis of MetS was reported; (4) Studies reported OR and weighted mean difference (WMD) with 95\% CI; (5) Studies (not case reports or meta-analyses) including estimation risk and initial data.

\section{Data Extraction and Quality Assessment}

Two independent investigators extracted the data from relevant studies while a third investigator resolved the discrepancy and reached a consensus. Data of risk factors in studies were extracted as follows: reference, year, country, study design, sample size, gender, mean age, mean BMI, MetS criteria, MetS prevalence, insulin, HOMA-IR, strain type, OR, and WMD with $95 \%$ CI. The methodological quality of primary studies was evaluated by the NewcastleOttawa Quality Assessment Scale. Bias analysis was necessary and studies with giant bias should be excluded.

\section{Statistical Analysis}

The software Stata 12.0 was applied to analyze the initial data. The data in this study was calculated as follows: (1) OR and WMD for binary and continuous data were abstracted, respectively. (2) Cochran's Q test and $I^{2}$ index were used to assess heterogeneity. $I^{2}$ values of $<30 \%, 30-59 \%, 60-75 \%$, and $\geq 75 \%$ were assumed to represent low, moderate, substantial, and considerable heterogeneity, respectively. (3) Subgroup analyses according to BMI classification, diagnostic criteria of MetS, geographical region, study design, and strain type were performed. (4) Sensitivity analysis was conducted and publication bias was estimated by Begg's and Egger's tests. 


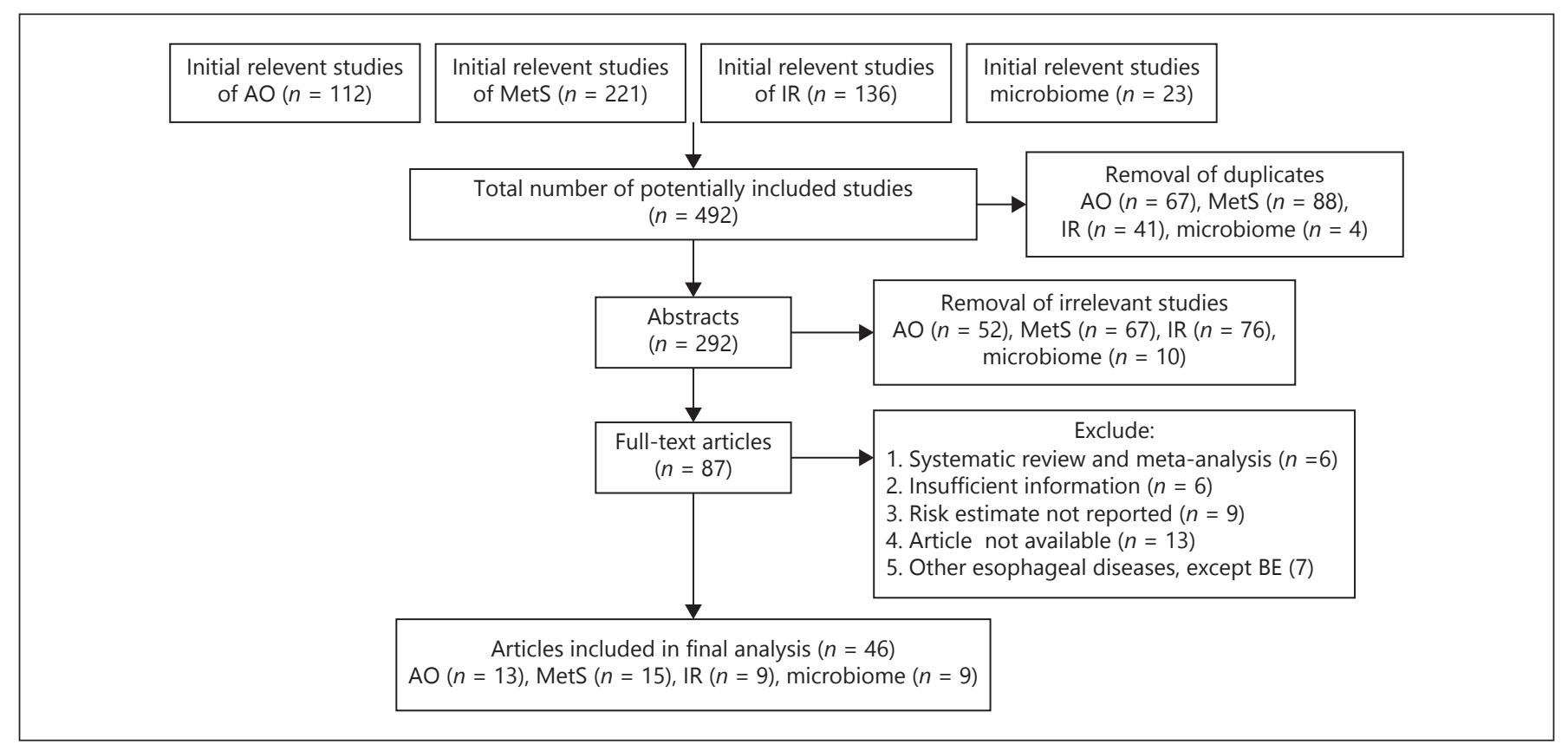

Fig. 1. Flow diagram of study selection. AO, abdominal obesity; MetS, metabolic syndrome; IR, insulin resistance; BE, Barrett's esophagus.

\section{Results}

Forty-six studies were included in the meta-analysis (Fig. 1).

\section{Association Between $A O$ and BE Risk}

The association between $\mathrm{AO}$ and $\mathrm{BE}$ risk was assessed by 13 studies which reported characteristics of study samples: country, study design, sex composition, age, WHR (men $>0.90$ and women $>0.85$ ), WC (men $>102 \mathrm{~cm}$ and women $>88 \mathrm{~cm})$, and BMI $\left(<25 \mathrm{~kg} / \mathrm{m}^{2}\right.$, $25 \mathrm{~kg} / \mathrm{m}^{2} \leq \mathrm{BMI}<30 \mathrm{~kg} / \mathrm{m}^{2}$, and $\left.\geq 30 \mathrm{~kg} / \mathrm{m}^{2}\right)$. The mean age of study samples ranged from 53.63 to 66.40 years old, and all sample populations were included in both men and women, except that one study was made up of a purely male population (online suppl. Table 1; for all online suppl. material, see www.karger.com/ doi/10.1159/000502376).

The overall effect revealed that AO significantly increased BE risk (OR 1.30, 95\% CI 1.11-1.52, Fig. 2a). Subgroup analysis was stratified by WHR, WC, BMI classification, geographic region, and study design. For subgroup analysis of WHR, the data of 4 citations showed a significantly increased risk of BE (OR 1.67, 95\% CI 1.35-2.07), of which was larger than 0.90 for men and 0.85 for women, while the rest of the citations were not available (Fig. 2b). Since the data of WHR were not sufficient, we compared the effect of WC on BE risk. $\mathrm{BE}$ risks of $\mathrm{WC}$ subgroups (men $>102 \mathrm{~cm}$ and women $>88 \mathrm{~cm}$; men $<102 \mathrm{~cm}$ and women $<88 \mathrm{~cm}$ ) were 1.35 (95\% CI 1.06-1.71) and 1.22 (95\% CI 0.55-2.74) times higher than the normal population, respectively (Fig. 2c). $\mathrm{BE}$ risks of populations whose $\mathrm{BMI} \geq 30 \mathrm{~kg} / \mathrm{m}^{2}(\mathrm{OR} 1.29$, $95 \%$ CI $1.04-1.59)$ and $25 \mathrm{~kg} / \mathrm{m}^{2} \leq \mathrm{BMI}<30 \mathrm{~kg} / \mathrm{m}^{2}(\mathrm{OR}$ $1.27,95 \%$ CI $0.95-1.72)$ were slightly stronger than that of BMI $<25 \mathrm{~kg} / \mathrm{m}^{2}$ (OR 1.20, 95\% CI 0.55-2.61, Fig. 2d). The increased risks were almost averagely distributed among the populations in world's continents: European population (OR 1.22, 95\% CI 0.83-1.78), North American population (OR 1.23, 95\% CI 1.01-1.50), Asian population (OR 1.22, 95\% CI 0.55-2.74, Fig. 2e). Comparing case-control studies with cohort studies, a 1.5-fold increased BE risk was observed (OR 1.38, 95\% CI 1.171.62, Fig. 2f). Moderate heterogeneity was present in all analyses $\left(I^{2}=31.9 \%\right)$, and there was no evidence of public bias $\left(\mathrm{P}_{\text {Begg's }}=0.86, \mathrm{P}_{\text {Egger's }}=0.93\right.$, online suppl. Fig. 1$)$. In the sensitivity analysis, there was no significant variation of associations by excluding one study in each turn.

\section{Association Between MetS and BE Risk}

MetS and BE risk was assessed by 15 studies with characteristics: country, study design, sample size, sex composition, age, prevalence, and diagnosis criteria which 


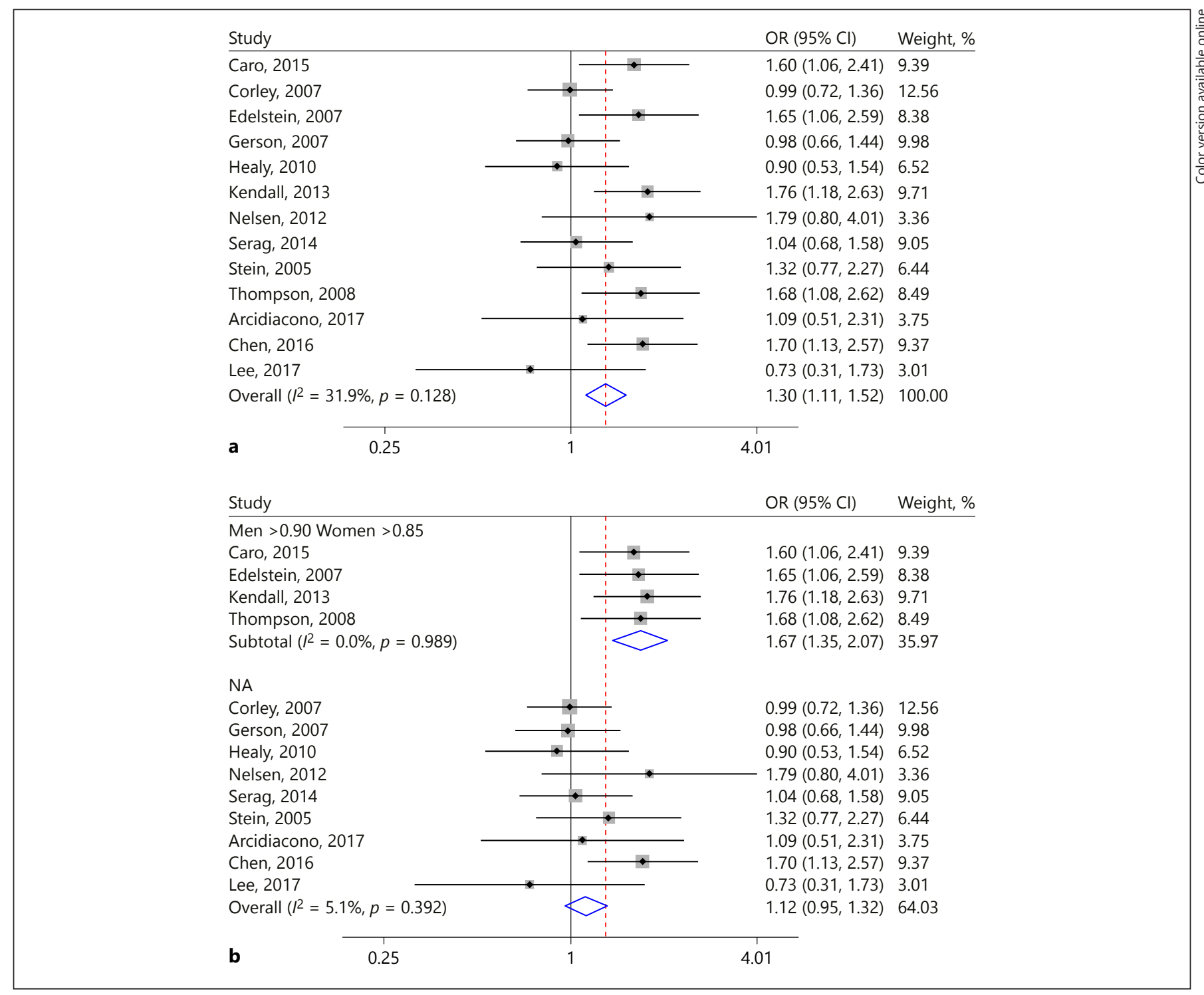

Fig. 2. Forest plot for the association between $A O$ and BE risk. a $\mathrm{AO}$ was significantly associated with $\mathrm{BE}(p<0.01)$. b-f Subgroup analyses were stratified by WHR, WC, BMI classification, geo-

could be classified into 4 categories (IDF, NCEP ATP III, both of IDF and NCEP ATP III, neither IDF nor NCEP ATP III). The average age of populations in studies ranged from 45.00 to 76.60 years old, and the prevalence of BE fluctuated between 0.87 and $64.51 \%$ (online suppl. Table 2).

MetS was associated with a significantly increased $\mathrm{BE}$ risk (OR 1.68, 95\% CI 1.40-2.01, Fig. 3a) with a considerable heterogeneity $\left(I^{2}=87.6 \%\right)$. In the subgroup analysis of diagnosis criteria, the criterion of neither NCEP ATP III nor IDF brought a significantly elevated BE risk graphic region, and study design. AO, abdominal obesity; BE, Barrett's esophagus; WHR, waist-to-hip ratio; WC, waist circumference; BMI, body mass index; NA, not available.

(Figure continued on next pages.)

(OR 4.94, 95\% CI 1.71-14.28) which was the highest among other diagnosis criteria, and BE risk in the criterion of IDF (OR 1.81, 95\% CI 1.60-2.05) was higher than that of NCEP ATP III (OR 1.36, 95\% CI 1.14-1.63). However, the criterion of both NCEP ATP III and IDF had taken the lowest BE risk (OR 0.94, 95\% CI 0.28-3.13, Fig. 3b). For subgroup analysis of geographic regions, European population had the highest BE risk (OR 2.35, 95\% CI 1.39-3.98) compared to Asia population (OR 1.75 , 95\% CI 1.58-1.94), while North American population carried the lowest BE risk (OR 1.42, 95\% CI 1.07- 


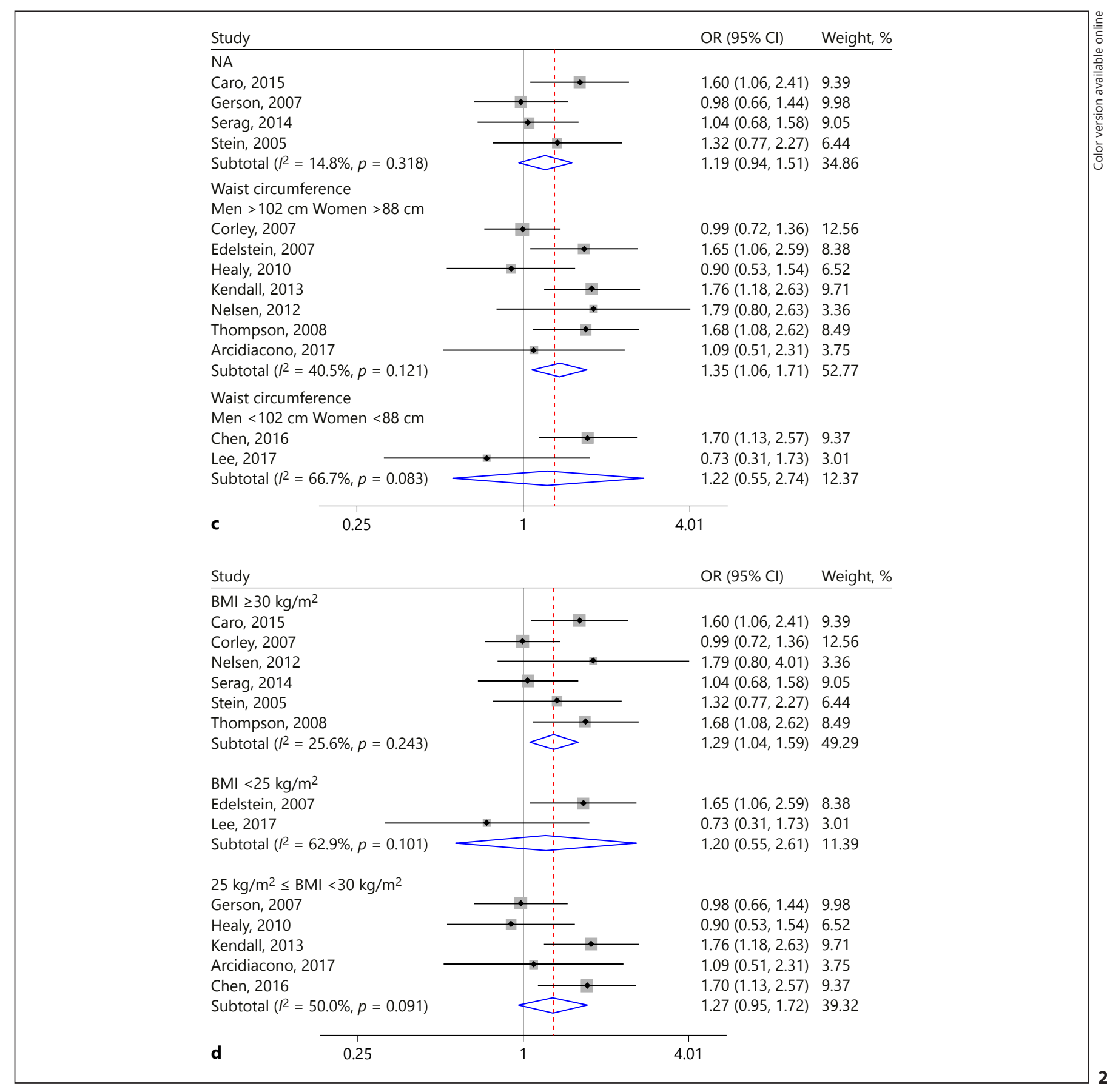

1.89, Fig. 3c). In study design analysis, case-control studies revealed a slightly higher risk than (OR 1.75, 95\% CI 1.41-2.17) cohort studies (OR 1.46, 95\% CI 0.89-2.39, Fig. 3d). Sensitivity analysis showed that the association was not driven by removing Drahos et al. [31]. No significant publication biases were detected by Egger's and Begg's test $\left(\mathrm{P}_{\text {Begg's }}=0.55, \mathrm{P}_{\text {Egger's }}=0.14\right.$, online suppl. Fig. 2).

The Relationship between BE and 4 Risk Factors

\section{Association Between IR and BE Risk}

IR with the association of BE risk was assessed by 9 studies, and we could observe the characteristics of study samples: country, study design, sample size, sex composition, age, insulin level, and HOMA-IR. The mean age of study samples ranged from 45.20 to 63.70 years old, and HOMA-IR was from 1.40 to 2.78 (online suppl. Table 3). 


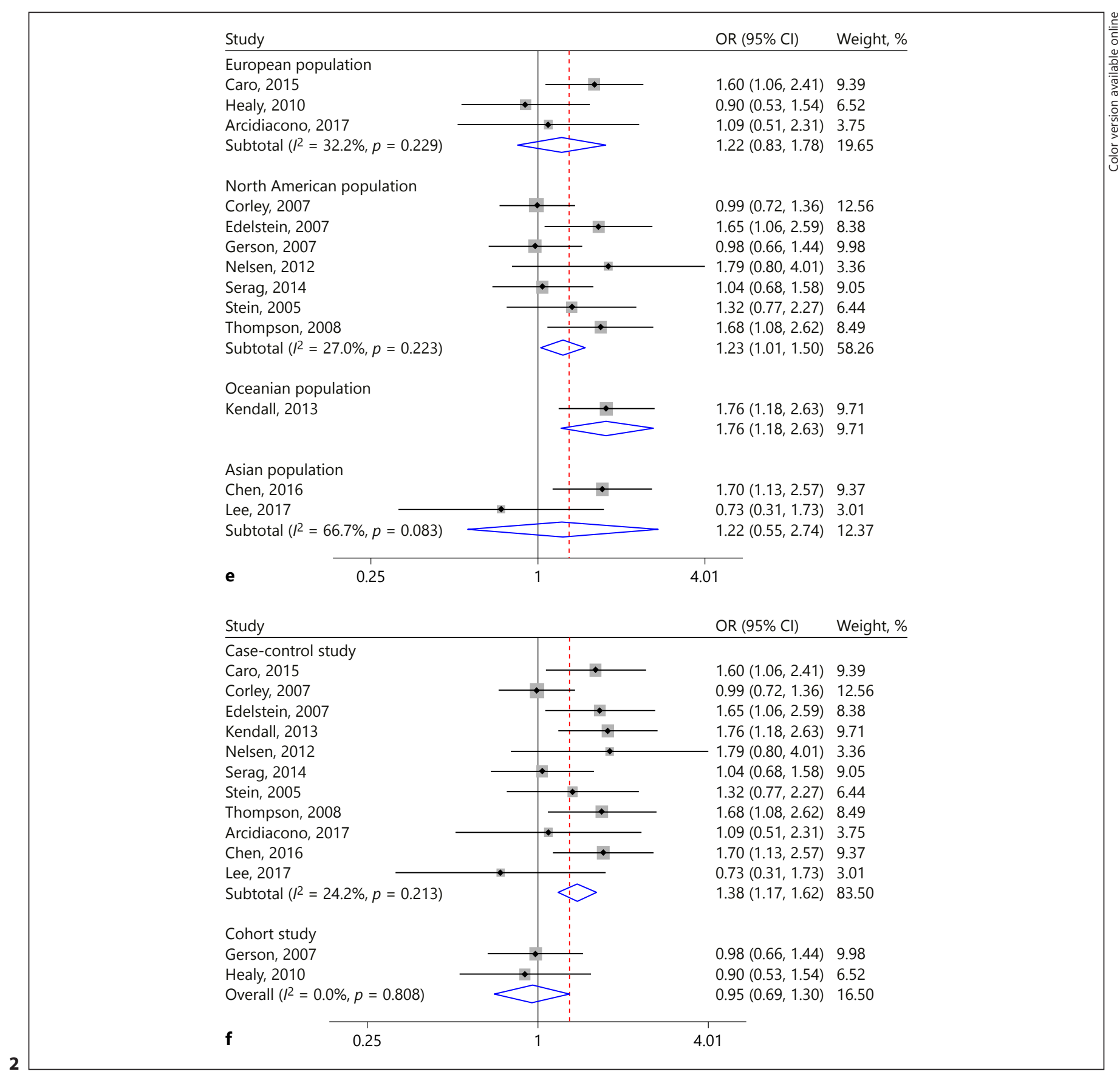

Our results indicated that IR was significantly associated with BE risk (WMD 0.23, 95\% CI 0.11-0.35, Fig. 4a). There was moderate heterogeneity $\left(I^{2}=55.8 \%\right)$. The subgroup analysis of geographic region demonstrated that an increased BE risk was found in the European population (WMD $0.25,95 \% \mathrm{CI}-0.12$ to 0.63 ) and Asian population (WMD 0.30, 95\% CI 0.14-0.46) which was a 2-fold risk compared with the North American population (WMD
$0.15,95 \%$ CI -0.02 to 0.31$)$. However, the Oceanian population showed an opposite association with BE risk, we blamed it on only one case of study (Fig. 4b). For study design, case-control studies were slightly associated with $\mathrm{BE}$ risk (WMD 0.27, 95\% CI 0.20-0.35), but cohort studies (WMD $-0.00,95 \%$ CI -0.36 to 0.36 ) did not show any promotion on BE risk (Fig. 4c). Sensitivity analysis showed no significant variations in the association of $\mathrm{BE}$ 
Fig. 3. Forest plot for the association between MetS and BE risk. a MetS was significantly associated with $\mathrm{BE}(p<0.01)$. b-d Subgroup analyses were stratified by diagnosis criteria, geographic region, and study design. MetS, metabolic syndrome; $\mathrm{BE}$, Barrett's esophagus.

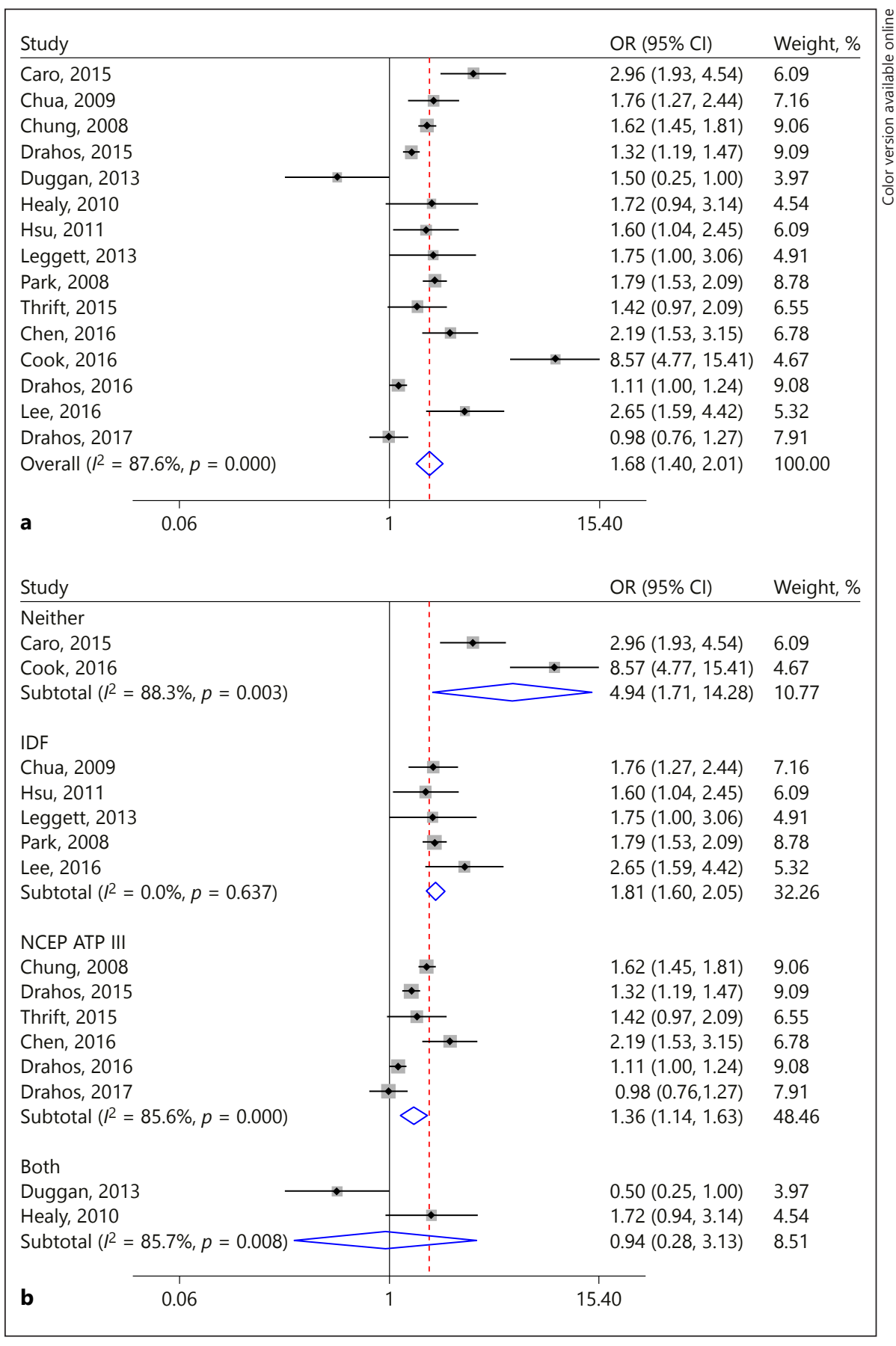

(Figure continued on next page.) risk. There were no significant publication biases in Egger's and Begg's test $\left(\mathrm{P}_{\text {Begg's }}=0.12, \mathrm{P}_{\text {Egger's }}=0.41\right.$, online suppl. Fig. 3).

\section{Association Between Microbiome and BE Risk}

The association between microbiome and BE risk was analyzed by 9 studies, and we summarized the character- istics of study samples: country, study design, sample size, sex composition, and age. Besides, there was a variety of strain types in the study samples, such as Proteobacteria, Campylobacter, Firmicutes, and Streptococcus.

Our results revealed that microbiome was not associated with BE risk ( $p=0.48$, Fig. $5 \mathrm{a})$ with a moderate heterogeneity $\left(I^{2}=46.7 \%\right)$. However, in the subgroup analy- 


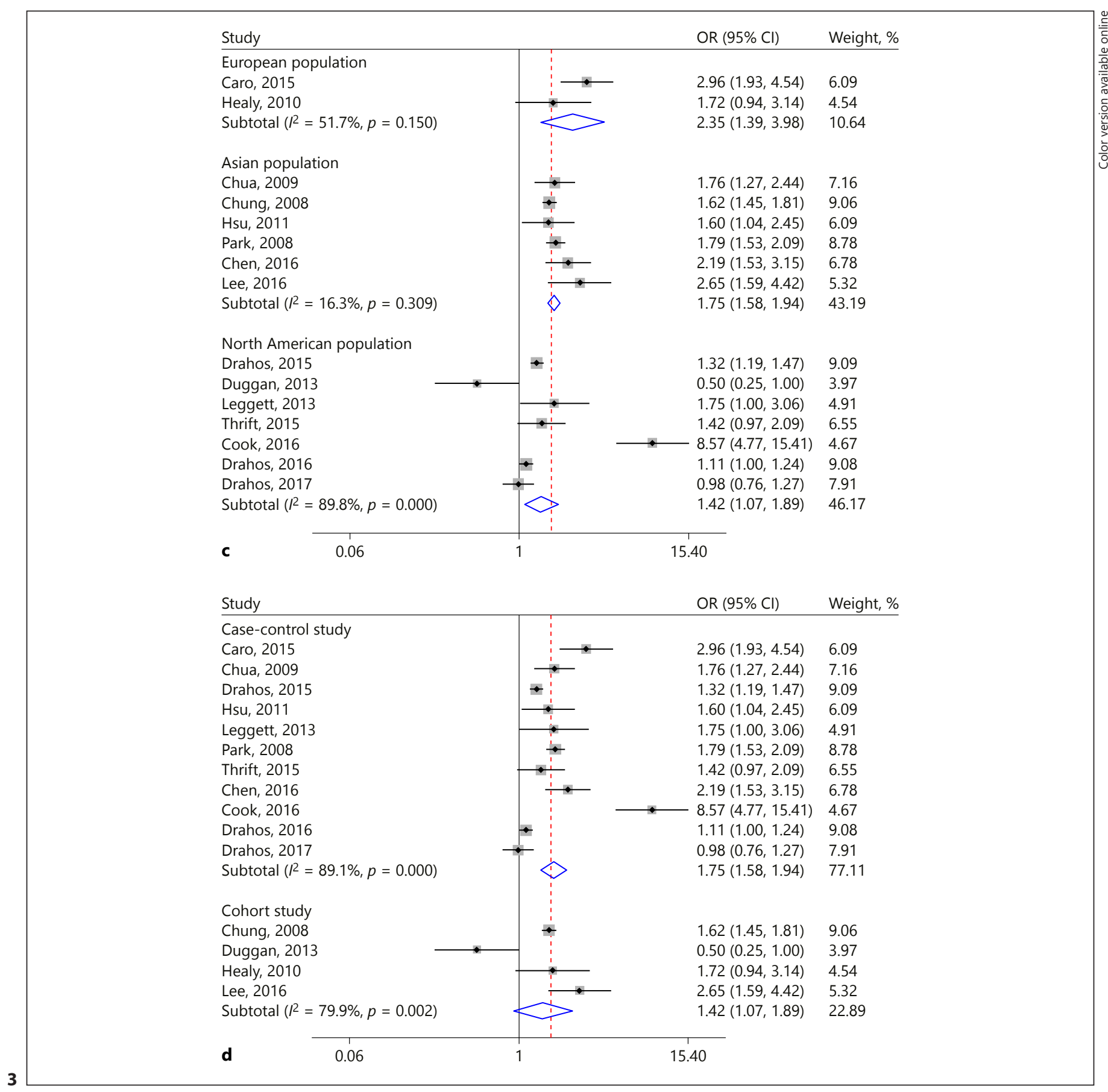

sis of strain type, Campylobacter showed a significantly increased risk for BE (OR 4.55, 95\% CI 1.73-11.95), which was 4.6 times higher than that of the healthy population. Proteobacteria was not related to BE risk, and other strains, such as Enterobacteriaceae, Firmicutes, and Streptococcus, did not reflect the risk for BE (Fig. 5b). For the subgroup analysis of study design, cohort studies showed an increased risk for BE (OR 2.17, 95\% CI 0.83-5.68), while case-control studies did not present an association (OR 0.88 , 95\% CI $0.38-2.02$, Fig. 5c). In the sensitivity analysis, we did not observe an obvious alteration in the association of $\mathrm{BE}$ risk. There were no publication biases in Egger's and Begg's tests $\left(\mathrm{P}_{\text {Begg's }}=0.47, \mathrm{P}_{\text {Egger's }}=0.72\right.$, online suppl. Fig. 4). 
Fig. 4. Forest plot for the association between IR and BE risk. a IR was significantly associated with BE $(p<0.01)$. b, c Subgroup analyses were stratified by geographic region and study design. IR, insulin resistance; $\mathrm{BE}$, Barrett's esophagus.

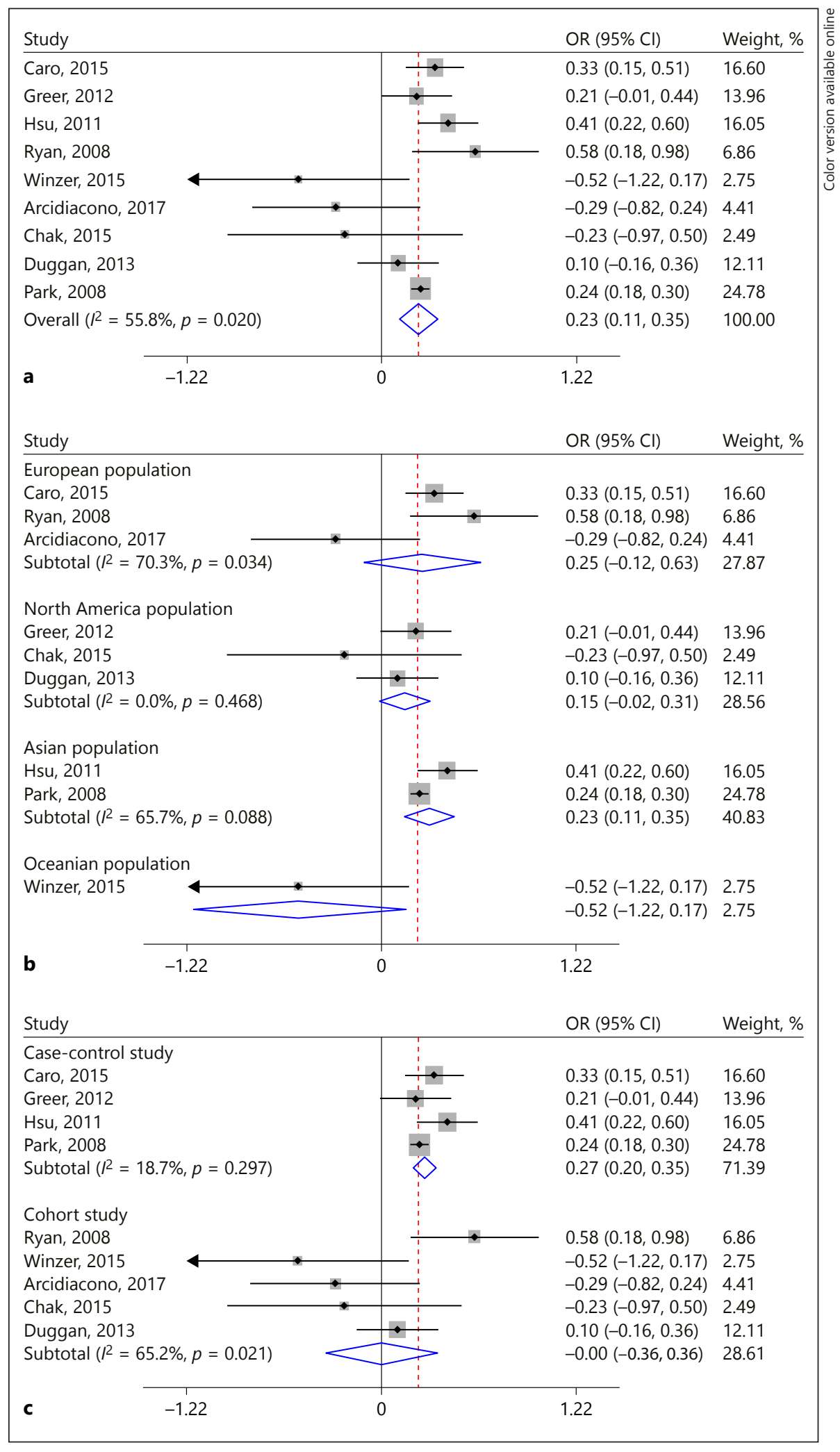

The Relationship between BE and 4 Risk Factors 
Fig. 5. Forest plot for the association between the microbiome and BE risk. a The microbiome was not associated with $\mathrm{BE}$ ( $p$ $>0.05)$. b, c Subgroup analyses were stratified by strain type and study design. BE, Barrett's esophagus.

\begin{tabular}{|c|c|c|c|c|}
\hline \multicolumn{3}{|c|}{ Study } & OR $(95 \% \mathrm{Cl})$ & Weight, \% \\
\hline \multicolumn{2}{|c|}{ Peters, 2017} & 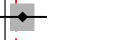 & $1.45(0.85,2.49)$ & 23.33 \\
\hline \multicolumn{2}{|c|}{ Amir, 2014} & 9 & $1.61(0.25,10.13)$ & 8.61 \\
\hline \multicolumn{2}{|c|}{ Snider, 2018} & : & $0.61(0.17,2.19)$ & 13.42 \\
\hline \multicolumn{2}{|c|}{ Yang, 2009} & $f_{1}^{\prime}$ & $0.13(0.01,1.20)$ & 6.57 \\
\hline \multicolumn{2}{|c|}{ Elliott, 2016} & is & $1.61(0.32,8.03)$ & 10.29 \\
\hline \multicolumn{2}{|c|}{ Macfarlane, 2007} & & $19.29(0.80,466.24)$ & 3.63 \\
\hline \multicolumn{2}{|c|}{ Blackett, 2013} & $\longrightarrow$ & $3.93(1.42,10.83)$ & 16.57 \\
\hline \multicolumn{2}{|c|}{ Ando, 2013} & $i$ & $1.33(0.15,11.93)$ & 6.69 \\
\hline \multicolumn{2}{|c|}{ Sawada, 2016} & is & $0.42(0.09,1.96)$ & 10.89 \\
\hline \multicolumn{2}{|c|}{ Overall $\left(R^{2}=46.7 \%, p=0.059\right)$} & & $1.27(0.66,2.43)$ & 100.00 \\
\hline a & 0.00214 & 1 & 0.00466 & \\
\hline \multicolumn{3}{|c|}{ Study } & OR $(95 \% \mathrm{Cl})$ & Weight, \% \\
\hline \multicolumn{2}{|c|}{ Other strains } & & & \\
\hline \multicolumn{2}{|c|}{ Peters, 2017} & $\because-$ & $1.45(0.85,2.49)$ & 23.33 \\
\hline \multicolumn{2}{|c|}{ Amir, 2014} & & $1.61(0.25,10.13)$ & 8.61 \\
\hline \multicolumn{2}{|c|}{ Yang, 2009} & $f$ & $0.13(0.01,1.20)$ & 6.57 \\
\hline \multicolumn{2}{|c|}{$\begin{array}{l}\text { Sawada, } 2016 \\
\text { subtotal }\left(R^{2}=51.9 \%, p=0.100\right)\end{array}$} & $\frac{1}{1}$ & $0.42(0.09,1.96)$ & 10.89 \\
\hline \multicolumn{2}{|c|}{ subtotal $\left(I^{2}=51.9 \%, p=0.100\right)$} & & $0.78(0.28,2.15)$ & 49.89 \\
\hline \multicolumn{5}{|c|}{ Proteobacteria } \\
\hline \multicolumn{2}{|c|}{ Snider, 2018} & & $0.61(0.17,2.19)$ & 13.42 \\
\hline \multicolumn{2}{|c|}{ Elliott, 2016} & 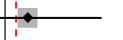 & $1.61(0.32,8.03)$ & 10.29 \\
\hline \multicolumn{2}{|c|}{ Ando, 2013} & 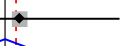 & $1.33(0.15,11.93)$ & 6.69 \\
\hline \multicolumn{2}{|c|}{ subtotal $\left(I^{2}=0.0 \%, p=0.618\right)$} & & $0.95(0.38,2.37)$ & 30.40 \\
\hline \multicolumn{5}{|c|}{ Campylobacter } \\
\hline \multicolumn{2}{|c|}{ Macfarlane, 2007} & & $19.29(0.80,466.24)$ & 3.63 \\
\hline & 013 & - & $3.93(1.42,10.83)$ & 16.57 \\
\hline & $2=0.0 \%, p=0.351)$ & & $4.55(1.73,11.95)$ & 20.20 \\
\hline $\mathbf{b}$ & 0.00214 & 1 & 0.00466 & \\
\hline$\underline{\text { Stu }}$ & & & OR $(95 \% \mathrm{Cl})$ & Weight, \% \\
\hline & & & & \\
\hline & & $\because-$ & $1.45(0.85,2.49)$ & 23.33 \\
\hline & 013 & - & $3.93(1.42,10.83)$ & 16.57 \\
\hline & $2=65.7 \%, p=0.088)$ & & $2.17(0.83,5.68)$ & 39.90 \\
\hline & rol study & & & \\
\hline & & - & $1.61(0.25,10.13)$ & 8.61 \\
\hline & & 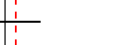 & $0.61(0.17,2.19)$ & 13.42 \\
\hline & - & $:$ & $0.13(0.01,1.20)$ & 6.57 \\
\hline & & : & $1.61(0.32,8.03)$ & 10.29 \\
\hline & e, 2007 & & $19.29(0.80,466.24)$ & 3.63 \\
\hline & & 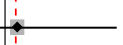 & $1.33(0.15,11.93)$ & 6.69 \\
\hline & & $\frac{1}{1}$ & $0.42(0.09,1.96)$ & 10.89 \\
\hline & $2=31.1 \%, p=0.191)$ & & $0.88(0.38,2.02)$ & 60.10 \\
\hline c & 0.00214 & 1 & 0.00466 & \\
\hline
\end{tabular}




\section{Discussion}

In this systematic analysis of 46 studies reporting on 119,273 subjects, we make sure that $\mathrm{AO}$, MetS, and IR are all significantly associated with $\mathrm{BE}$.

AO: Recent studies have shown that $\mathrm{AO}$ measured by WHR and WC, which are better than BMI, is involved in the progression to $\mathrm{BE}$ and $\mathrm{EAC}[10,32,33]$. The WHO states that WHR which belongs to AO is above 0.90 for males and above 0.85 for females, respectively [34]. For subgroup analysis of WHR, the data extracted from the available citations were all significantly higher than that of the WHO standard. The results indicated that AO measured by WHR which was greater than the WHO standard was a key factor for the risk of BE. Due to insufficient data of WHR, we also performed the subgroup analysis of $\mathrm{WC}$ as a supplementary explanation. $\mathrm{AO}$ is determined as WC of above $102 \mathrm{~cm}$ for men and above $88 \mathrm{~cm}$ for women [35]. The WC of the obese population showed a higher risk of BE than that of a healthy population, which was consistent with other studies [36, 37]. Interestingly, we observed that the $\mathrm{WC}$ of the healthy population also had 1.22 times of BE risk, while we originally supposed that the healthy population with normal WC were not easy to suffer from BE. We attributed the opposite conclusion to a few citations (only 2 citations). In addition to WHR and WC, BMI is also used to measure AO. Subgroup analysis stratified by BMI classification revealed that obese population $\left(B M I \geq 30 \mathrm{~kg} / \mathrm{m}^{2}\right)$ and overweight/pre-obese population $\left(25 \mathrm{~kg} / \mathrm{m}^{2} \leq \mathrm{BMI}\right.$ $<30 \mathrm{~kg} / \mathrm{m}^{2}$ ) had a higher BE risk than underweight or healthy people (BMI $<25 \mathrm{~kg} / \mathrm{m}^{2}$ ), the results were similar to other studies $[8,29]$. According to the subgroup analysis of the geographical region, European, North American, and Asian populations were proved to have same risks of $\mathrm{BE}$, but Oceanian populations were more likely to suffer from BE than other populations, we blamed the reason to the insufficient number of study. The result was significant in case-control studies, but not in cohort studies. It might originate from a random error, so it was necessary to include more studies in cohort studies.

MetS: MetS includes a series of metabolic disorders, such as the large waistline, high triglyceride, low levels of high-density lipoprotein cholesterol, high blood pressure, and elevated levels of fasting blood sugar. It has been considered as a risk factor for gastrointestinal diseases such as gastroesophageal reflux disease and $\mathrm{BE}$ [38-40]. Similarly, our results proved that MetS was an important contributor to $\mathrm{BE}$, but the heterogeneity was considerable. We speculated that the heterogeneity was

The Relationship between BE and 4 Risk Factors derived from the included citations, especially from the citations Cook 2016 and Duggan 2013, because the ORs of these 2 citations were almost inconsistent with others. In addition, our subgroup analysis of diagnosis criteria (NCEP ATP III and IDF) demonstrated that the neither-subgroup and the both-subgroup showed the considerable heterogeneity due to containing the citations Cook 2016 and Duggan 2013, although NCEP ATP III and IDF themselves might not be one of the sources of the heterogeneity. The subgroup analyses of the geographic region and study design also revealed that the considerable heterogeneity in the North American population and study designs are derived from Cook 2016 to Duggan 2013. Apart from these 2 citations, the result of the sensitivity analysis did not show significant variations in the association of BE risk by removing Drahos 2016, which demonstrated that Drahos 2016 was not the resource of the considerable heterogeneity.

$I R:$ IR is defined as the inability of a quantity of exogenous or endogenous insulin to increase glucose uptake and utilization in a normal population [41]. Some scholars have confirmed the association between IR and BE $[42,43]$. In addition, patients with BE are more likely to develop EAC with higher levels of leptin and IR [44]. As stated above, our studies also confirmed that IR was associated with BE. In the subgroup analysis based on geographical regions, BE risk was significant in Asian, North American, and European populations, but except for Oceania population. Only one observational study was conducted in Oceania population [45], which might limit the accuracy of the pooled estimates. The association between IR and BE risk appeared only in case-control studies, but cohort studies did not show any evidence that IR was a risk factor for BE.

Microbiome: Microbiome is a rapidly advancing research topic in BE and EAC [46-48]. Some researchers believe that microbiome is a key factor in the pathological process of $\mathrm{BE}$, while others hold the opposite opinion $[48,49]$. Our results revealed that the microbiome did not have a significant association with $\mathrm{BE}$ risk, but had a tendency to become a risk factor for BE. Although the overall result was negative, we observed a positive result by the subgroup analysis of strain types. Microbiome alterations were mainly concentrated in Campylobacter and Proteobacteria, and Campylobacter was significantly associated with the risk of BE, while Proteobacteria might not be related to BE risk. Based on the negative results, we speculated that this association would be more accurate with more citations. Additionally, the overall negative results with subgroup positive 
results indicated that individualized analysis of esophageal microbiome was an inevitable step in the diagnosis of BE.

Our study reveals that AO, MetS, and IR are significantly associated with BE risk, except for microbiome. These risk factors should be seriously considered when diagnosing and preventing $\mathrm{BE}$ and associated adenocarcinoma in clinical practice. However, it is still unclear how these factors induce metaplastic transformation in the human esophageal epithelium, which should be further explored.

\section{Acknowledgment}

This work was supported by the National Natural Science Foundation of China (No. 81700474) and the Science and Technology Research Foundation of Xi' an Jiaotong University of China (Nos. YJ-ZD 201520 and YJ-ZD 201411).

\section{Statement of Ethics}

Approval for the publication of this meta-analysis has been obtained from the Ethics Committee of Xi'an Jiaotong University (Certificate No. 2018-1034). All the procedures in the study involving human material and data were performed in accordance with World Medical Association's Declaration of Helsinki-Ethical Principles for Medical Research Involving Human Subject.

\section{Disclosure Statement}

The authors have no conflict of interest.

\section{Author Contributions}

Y.C. designed experiments; J.D. carried out experiments and analyzed experimental results; D.C. and Y.L. collected experimental data; J.D. wrote the manuscript.

\section{References}

1 Spechler SJ. Barrett esophagus and risk of esophageal cancer: a clinical review. JAMA. 2013 Aug;310(6):627-36.

2 Hagen CE, Lauwers GY, Mino-Kenudson M. Barrett esophagus: diagnostic challenges. Semin Diagn Pathol. 2014 Mar;31(2):100-13.

3 Tadiparthi R, Bansal A, Sharma P. What's new in columnar lined esophagus (Barrett's metaplasia)? Curr Opin Gastroenterol. 2008 Jul;24(4):516-20.

4 Shiota S, Singh S, Anshasi A, El-Serag HB. Prevalence of Barrett's Esophagus in Asian Countries: A Systematic Review and Metaanalysis. Clin Gastroenterol Hepatol. 2015 Nov;13(11):1907-18.

5 Falk GW, Jacobson BC, Riddell RH, Rubenstein JH, El-Zimaity H, Drewes AM, et al. Barrett's esophagus: prevalence-incidence and etiology-origins. Ann N Y Acad Sci. 2011 Sep; 1232(1):1-17.

6 Shaheen NJ, Falk GW, Iyer PG, Gerson LB; American College of Gastroenterology. ACG Clinical Guideline: Diagnosis and Management of Barrett's Esophagus. Am J Gastroenterol. 2016 Jan;111(1):30-50.

7 Thrift AP. Determination of risk for Barrett's esophagus and esophageal adenocarcinoma. Curr Opin Gastroenterol. 2016 Jul;32(4):31924.

8 Kendall BJ, Macdonald GA, Hayward NK, Prins JB, O'Brien S, Whiteman DC; Study of Digestive Health. The risk of Barrett's esophagus associated with abdominal obesity in males and females. Int J Cancer. 2013 May; 132(9):2192-9.

9 Drahos J, Ricker W, Pfeiffer RM, Cook MB. Metabolic syndrome and risk of esoph- ageal adenocarcinoma in elderly patients in the United States: an analysis of SEERMedicare data. Cancer. 2017 Feb;123(4): 657-65.

10 Chandar AK, Iyer PG. Role of Obesity in the Pathogenesis and Progression of Barrett's Esophagus. Gastroenterol Clin North Am. 2015 Jun;44(2):249-64.

11 Baghdadi J, Chaudhary N, Pei Z, Yang L. Microbiome, innate immunity, and esophageal adenocarcinoma. Clin Lab Med. 2014 Dec; 34(4):721-32.

12 Hunt RH, Yaghoobi M. The Esophageal and Gastric Microbiome in Health and Disease. Gastroenterol Clin North Am. 2017 Mar; 46(1):121-41.

13 Sanghi V, Thota PN. Barrett's esophagus: novel strategies for screening and surveillance. Ther Adv Chronic Dis. 2019 Mar; 10: 2040622319837851.

14 Hu L, Huang X, You C, Li J, Hong K, Li P, et al. Prevalence of overweight, obesity, abdominal obesity and obesity-related risk factors in southern China. PLoS One. 2017 Sep;12(9): e0183934.

15 Du X, Hidayat K, Shi BM. Abdominal obesity and gastroesophageal cancer risk: systematic review and meta-analysis of prospective studies. Biosci Rep. 2017 May;37(3):37.

16 Zafar U, Khaliq S, Ahmad HU, Manzoor S, Lone KP. Metabolic syndrome: an update on diagnostic criteria, pathogenesis, and genetic links. Hormones (Athens). 2018 Sep;17(3): 299-313.

17 Oda E. Historical perspectives of the metabolic syndrome. Clin Dermatol. 2018 Jan-Feb; 36(1):3-8.
18 Wang G. Raison d'être of insulin resistance: the adjustable threshold hypothesis. J R Soc Interface. 2014 Dec;11(101):20140892.

19 Tang Q, Li X, Song P, Xu L. Optimal cut-off values for the homeostasis model assessment of insulin resistance (HOMA-IR) and pre-diabetes screening: developments in research and prospects for the future. Drug Discov Ther. 2015 Dec;9(6):380-5.

20 Clemons NJ, Phillips WA, Lord RV. Signaling pathways in the molecular pathogenesis of adenocarcinomas of the esophagus and gastroesophageal junction. Cancer Biol Ther. 2013 Sep;14(9):782-95.

21 May M, Abrams JA. Emerging Insights into the Esophageal Microbiome. Curr Treat Options Gastroenterol. 2018 Mar;16(1):7285.

22 Zaidi AH, Kelly LA, Kreft RE, Barlek M, Omstead AN, Matsui D, et al. Associations of microbiota and toll-like receptor signaling pathway in esophageal adenocarcinoma. BMC Cancer. 2016 Feb;16(1):52.

23 Munch NS, Fang HY, Ingermann J, Maurer HC, Anand A, Kellner V, et al. High-fat Diet Accelerates Carcinogenesis in a Mouse Model of Barrett's Esophagus via Interleukin 8 and Alterations to the Gut Microbiome. Gastroenterology. 2019 Aug; 157(2): 492-506.e2.

24 Matsuzaki J, Suzuki H, Kobayakawa M, Inadomi JM, Takayama $\mathrm{M}$, Makino $\mathrm{K}$, et al. Association of Visceral Fat Area, Smoking, and Alcohol Consumption with Reflux Esophagitis and Barrett's Esophagus in Japan. PLoS One. 2015 Jul; 10(7): $\mathrm{e} 0133865$. 
25 He Q, Li JD, Huang W, Zhu WC, Yang JQ. Metabolic syndrome is associated with increased risk of Barrett esophagus: A metaanalysis. Medicine (Baltimore). 2016 Aug; 95(31):e4338.

26 Holub JL, Silberg DG, Michaels LC, Williams JL, Morris CD, Eisen G. Acid-related upper endoscopy findings in patients with diabetes versus non-diabetic patients. Dig Dis Sci. 2010 Oct:55(10):2853-9.

27 Blackett KL, Siddhi SS, Cleary S, Steed H, Miller MH, Macfarlane S, et al. Oesophageal bacterial biofilm changes in gastro-oesophageal reflux disease, Barrett's and oesophageal carcinoma: association or causality? Aliment Pharmacol Ther. 2013 Jun;37(11):1084-92.

28 Liu N, Ando T, Ishiguro K, Maeda O, Watanabe O, Funasaka K, et al. Characterization of bacterial biota in the distal esophagus of Japanese patients with reflux esophagitis and Barrett's esophagus. BMC Infect Dis. 2013 Mar; 13(1):130.

29 El-Serag HB, Hashmi A, Garcia J, Richardson P, Alsarraj A, Fitzgerald S, et al. Visceral abdominal obesity measured by CT scan is associated with an increased risk of Barrett's oesophagus: a case-control study. Gut. $2014 \mathrm{Feb}$; 63(2):220-9.

30 Sawada A, Fujiwara Y, Nagami Y, Tanaka F, Yamagami H, Tanigawa T, et al. Alteration of Esophageal Microbiome by Antibiotic Treatment Does Not Affect Incidence of Rat Esophageal Adenocarcinoma. Dig Dis Sci. 2016 Nov;61(11):3161-8.

31 Drahos J, Ricker W, Pfeiffer RM, Cook MB. Metabolic syndrome and risk of esophageal adenocarcinoma in elderly patients in the United States: an analysis of SEER-Medicare data. Cancer. 2017 Feb;123(4):657-65.

32 Kramer JR, Fischbach LA, Richardson P, Alsarraj A, Fitzgerald S, Shaib Y, et al. Waistto-hip ratio, but not body mass index, is as- sociated with an increased risk of Barrett's esophagus in white men. Clin Gastroenterol Hepatol. 2013;11:373-81.e371.

33 Akiyama T, Yoneda M, Maeda S, Nakajima A, Koyama S, Inamori M. Visceral obesity and the risk of Barrett's esophagus. Digestion. 2011;83(3):142-5.

34 Nishida C, Ko GT, Kumanyika S. Body fat distribution and noncommunicable diseases in populations: overview of the 2008 WHO Expert Consultation on Waist Circumference and Waist-Hip Ratio. Eur J Clin Nutr. 2010 Jan;64(1):2-5.

35 Slattery ML, Ferucci ED, Murtaugh MA, Edwards S, Ma KN, Etzel RA, et al. Associations among body mass index, waist circumference, and health indicators in American Indian and Alaska Native adults. Am J Health Promot. 2010 Mar-Apr;24(4):246-54

36 Mitchell DR, Derakhshan MH, Wirz AA, Ballantyne SA, McColl KE. Abdominal Compression by Waist Belt Aggravates Gastroesophageal Reflux, Primarily by Impairing Esophageal Clearance. Gastroenterology. 2017 Jun;152(8):1881-8.

37 Lee SW, Lien HC, Lee TY, Tung CF, Yeh HZ, Chang CS. Impact of Obesity on a Chinese Population with Erosive Esophagitis and Barrett's Esophagus. Gut Liver. 2017 May;11(3):377-82.

38 Lin XH, Luo JC. Metabolic syndrome and gastrointestinal-hepatobiliary diseases. J Chin Med Assoc. 2017 Jan;80(1):3-4.

39 Cadman L, Nelsen EM, Tian J, Schleck C, Zinsmeister AR, Locke GR, et al. Metabolic Syndrome is a Risk Factor for Barrett's Esophagus: A Population Based Case Control Study. Gastroenterology. 2011;140(5):140.

40 Veugelers PJ, Porter GA, Guernsey DL, Casson AG. Obesity and lifestyle risk factors for gastroesophageal reflux disease, Barrett esophagus and esophageal adenocarcinoma. Dis Esophagus. 2006;19(5):321-8.
41 Lebovitz HE. Insulin resistance: definition and consequences. Exp Clin Endocrinol Diabetes. 2001;109(suppl 2):S135-48.

42 Greer KB, Thompson C, Brenner L, Bednarchik B, Falk GW, Grady WM, et al. 15 Insulin Resistance and Central Adiposity as a Risk Factors for Barrett's Esophagus. Gastroenterology. 2010;138(5):S-2.

43 Thrift AP, Hilal J, El-Serag HB. Metabolic syndrome and the risk of Barrett's oesophagus in white males. Aliment Pharmacol Ther. 2015 Jun;41(11):1182-9.

44 Charmandari E, Weise M, Bornstein SR, Eisenhofer G, Keil MF, Chrousos GP, et al. Children with classic congenital adrenal hyperplasia have elevated serum leptin concentrations and insulin resistance: potential clinical implications. J Clin Endocrinol Metab. 2002 May;87(5):2114-20.

45 Winzer BM, Paratz JD, Whitehead JP, Whiteman DC, Reeves MM. The feasibility of an exercise intervention in males at risk of oesophageal adenocarcinoma: a randomized controlled trial. PLoS One. 2015 Feb;10(2): e0117922.

46 Wang ZK, Yang YS. Upper gastrointestinal microbiota and digestive diseases. World J Gastroenterol. 2013 Mar;19(10):1541-50.

47 Baba Y, Iwatsuki M, Yoshida N, Watanabe M, Baba H. Review of the gut microbiome and esophageal cancer: pathogenesis and potential clinical implications. Ann Gastroenterol Surg. 2017 Jun;1(2):99-104.

48 Ajayi TA, Cantrell S, Spann A, Garman KS Barrett's esophagus and esophageal cancer: links to microbes and the microbiome. PLoS Pathog. 2018 Dec;14(12):e1007384.

49 Snider EJ, Compres G, Freedberg DE, Giddins MJ, Khiabanian $\mathrm{H}$, Lightdale CJ, et al. Barrett's esophagus is associated with a distinct oral microbiome. Clin Transl Gastroenterol. 2018 Feb;9(3):135. 